\title{
Assessment of left atrial dimensions by cross sectional echocardiography in patients with mitral valve disease
}

\author{
FRANCESCO LOPERFIDO, FAUSTINO PENNESTRI, ALESSANDRO DIGAETANO, \\ ENRICO SCABBIA, PIETRO SANTARELLI, ROCCO MONGIARDO, GIOVANNI \\ SCHIAVONI, ELDA COPPOLA, UGO MANZOLI
}

From the Department of Cardiology, Catholic University S Cuore, Rome, Italy

SUMMARY Left atrial dimensions were measured using cross sectional echocardiography in 37 patients with mitral valve disease and 30 normal subjects of similar ages. The anteroposterior (AP), superior-inferior (SI), and medial-lateral (ML) left atrial dimensions were determined at the end of ventricular systole using parasternal long and short axis and apical four chamber views (for SIa and $\mathrm{MLa}$ ). To assess the reliability of these measurements cross sectional echocardiographic and angiographic left atrial volumes were compared in 19 patients with mitral valve disease, giving an excellent correlation. A moderate correlation was found between the anteroposterior dimension of the left atrium obtained using $M$ mode echocardiography and that obtained using the parasternal short axis and long axis projections.

In normal subjects a good correlation was found between SI and ML dimensions, while a lower correlation was found between SI and AP, and ML and AP dimensions. The SI dimension was the major axis of the left atrium and AP dimension the minor axis. In patients with mitral valve disease a good correlation was found between SI and ML dimensions, while SI and ML dimensions had a low correlation with AP dimensions. The AP dimension was the minor axis of the left atrium, while the SI and ML dimensions were not significantly different. All left atrial dimensions were significantly greater in patients with mitral valve disease than in normal subjects. Of 30 patients with at least one dimension increased, all three dimensions were abnormal in 16, two dimensions were increased in 10 , and only one dimension was increased in four. AP, SI, and ML dimensions were abnormal in 25, 20, and 27 patients, respectively.

Cross sectional echocardiography may provide a reliable estimate of left atrial dimensions. In patients with mitral valve disease a thorough examination of the left atrium using multiple cross sectional views is necessary to detect asymmetric left atrial enlargement and to measure the degree of left atrial dilatation.

$M$ mode echocardiography is a reliable method of obtaining a non-invasive estimate of the left atrial anteroposterior dimension. ${ }^{1-4}$ Its usefulness for estimating left atrial volume, however, may be limited because the left atrium is usually elliptical rather than spherical. ${ }^{56}$ Examples of substantial asymmetry of the left atrium have been reported in subjects with normal sized or enlarged left atria. ${ }^{7-10}$ In such cases the left atrial anteroposterior (AP) dimension alone is not accurate for left atrial volume assessment. ${ }^{11}$

Cross sectional echocardiography allows visualisa-

Accepted for publication 19 July 1983 tion of the entire left atrium from different views. ${ }^{1-13}$ Schabelman et al. ${ }^{14}$ on the basis of angiographic comparison, established that cross sectional echocardiographic estimation of the left atrial volume is superior to that obtained on $M$ mode echocardiography, which is based on a cubic anteroposterior dimension. Feigenbaum ${ }^{11}$ suggested that with increased quality of echocardiographic recordings cross sectional echocardiography would be superior to the $M$ mode examination of left atria.

Previous studies have shown that cross sectional echocardiography is accurate for measuring right atrial size. ${ }^{1516} \mathrm{Few}$ data have been reported on the cross sectional echocardiographic estimate of left 
atrial enlargement ${ }^{12-14}$ and on the prevalence of asymmetric left atrial dilatation. ${ }^{11}$

The purposes of this study were, firstly, to evaluate the reliability of cross sectional echocardiographic estimates of left atrial size by comparing them with angiographic volumes in 19 patients with mitral valve disease and, secondly, to provide an analysis of left atrial configuration by cross sectional echocardiography in normal subjects and in patients with mitral valve disease.

\section{Patients and methods}

Sixty one consecutive patients with mitral valve disease ( 33 women and 28 men) were studied using $M$ mode and cross sectional echocardiography. Patients' ages ranged from 19 to 66 years (mean $\pm S D=42 \pm 9$ years). Patients in whom the quality of the cross sectional echocardiogram was not adequate to obtain measurements of all left atrial dimensions were excluded from subsequent analysis.

The resulting group constituted 37 patients-20 women and 17 men-with ages ranging from 21 to 66 years. Table 1 shows the clinical data for these 37 patients. Twenty eight patients underwent cardiac catheterisation, and in 19 of these a good left atrial angiogram was obtained.

Thirty four healthy subjects were also studied. Criteria for inclusion were normal physical examination and electrocardiogram. Thirty of them (13 women and $17 \mathrm{men}$ ), ages ranging from 17 to 59 years (mean \pm SD 39.6 $\pm 10 \cdot 1$ years), had technically satisfactory $M$ mode and cross sectional echocardiography 1718 and they constituted the control group.

\section{MODE ECHOCARDIOGRAPHY}

$M$ mode echocardiograms of the left atrium were recorded on strip chart using an Irex II system and a $2.25 \mathrm{MHz}, 1.25$ inch diameter unfocused transducer with the patient in the supine or left semilateral position. The anteroposterior left atrial dimension was taken from the leading edge of the posterior aortic root to the leading edge of the posterior left atrial wall at the maximum upward motion of the aortic wall. ${ }^{18}$ Mean values from three consecutive cardiac cycles were calculated. The $M$ mode echocardiographic measurements were taken separately from the cross sectional echocardiographic recordings.

\section{CROSS SECTIONAL ECHOCARDIOGRAPHY}

Cross sectional echocardiograms of the left atrium were obtained using a commercially available real time phased array ultrasonic system (Irex III) with a 32 crystal transducer operating at $2.5 \mathrm{MHz}$ in a sector of $80^{\circ}$. The studies were recorded on a half inch Sony cassette videotape for subsequent review in real time,
Table 1 Clinical and cardiac catheterisation data in the 37 patients with mitral valve disease and adequate cross sectional echocardiograms

\begin{tabular}{|c|c|c|}
\hline & $\begin{array}{l}\text { Mitral valve } \\
\text { stemosis (with } \\
\text { or without mitral } \\
\text { valve regungitation) }\end{array}$ & $\begin{array}{l}\text { Pure mitral } \\
\text { valve } \\
\text { regurgitation }\end{array}$ \\
\hline \multirow{7}{*}{$\begin{array}{l}\text { No. of patients } \\
\text { Sinus rhythm } \\
\text { Atrial fibrillation } \\
\text { Cardiac catheterisation } \\
\text { No. of patients } \\
\text { Mitral valve regurgitation } \\
\text { grade } 0 \\
\text { Mitral valve regurgitation } \\
\text { grade } 1 \\
\text { Mitral valve regurgitation } \\
\text { grade } 2 \\
\text { Mitral valve regurgitation } \\
\text { grade } 3 \\
\text { Aortic valve stenosis } \\
\text { Aortic valve regurgitation }\end{array}$} & $\begin{array}{r}26 \\
17 \\
9\end{array}$ & $\begin{array}{r}11 \\
5 \\
6\end{array}$ \\
\hline & & \\
\hline & 21 & 7 \\
\hline & 13 & 0 \\
\hline & 4 & 0 \\
\hline & 3 & 4 \\
\hline & $\begin{array}{l}1 \\
5 \\
4\end{array}$ & $\begin{array}{l}3 \\
2 \\
2\end{array}$ \\
\hline
\end{tabular}

Mitral valve regurgitation graded according to Sellers et al. ${ }^{22}$

slow motion, or single frame presentation.

The examination included the following cross sectional planes: (1) parasternal long axis view; (2) parasternal short axis view; and (3) apical four chamber view. ${ }^{19}$ Subcostal examination of the left atrium was not performed since it is not sufficiently standardised. ${ }^{13}$

Parasternal imaging of the left atrium was obtained with the patient in the supine or left semilateral position by placing the transducer at the third or fourth intercostal space. In the long axis view care was taken to visualise clearly the upper limits of the atrium. ${ }^{13}$ The short axis view was recorded by positioning the transducer immediately over the plane of transition of the mitral valve anterior leaflet echo into the posterior aortic root echo. Care was taken to visualise exactly the outer boundaries of the left atrium by minimal changes of the transducer angulation along the azimuthal plane. The four chamber apical view was recorded by placing the transducer directly on the apical impulse with the patient in the left lateral position.

For each view the transducer was angled to maximise the left atrial size. Consequently, both the parasternal and the apical windows varied from patient to patient. For the parasternal approach we tended to place the transducer at a higher interspace than that used in the standard studies so as to identify better the left atrial outlines. Clear echoes of the cavity boundaries were obtained by optimising grey scale and adjusting the controls to view the endocardium at the lowest possible gain.

For quantitative analysis the frozen images were traced from videotape on to clear plastic using a commercially available light pen system controlled by 


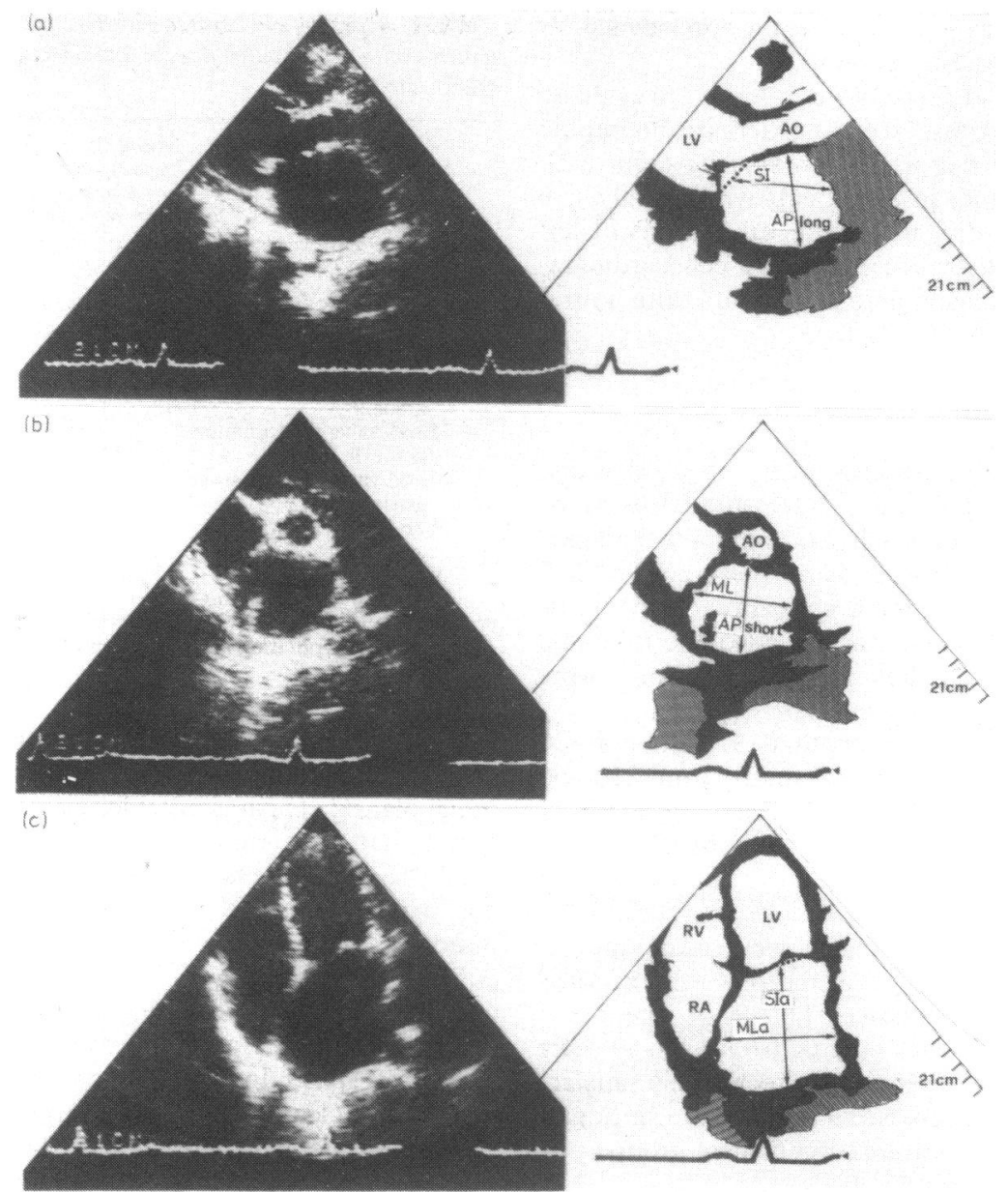

Fig. 1 Left atrial dimensions measured from the parasternal long axis (a), parasternal short axis (b), and apical four chamber (c) views.

$A P$, anteroposterior dimension; $S I$, superior-inferior dimension; $M L$, medial-lateral dimension; $a$, apical; $L V$, left ventricle; $R V$, right ventricle; $R A$, right atrium; $A O$, aorta.

a microprocessor (Irex Cardio 80). Brightness and contrast of the television monitor were adjusted to optimise the performance of the light pen system.

In order to compare the left atrial dimensions obtained from different cross sectional views or approaches, the following were measured ${ }^{13}$ (Fig. 1): (1) Anteroposterior dimensions in the parasternal long axis (AP long) and short axis (AP short) views; (2) superior-inferior dimensions in the parasternal long axis (SI) and apical four chamber (SIa) views; (3) medial-lateral dimensions in the parasternal short axis (ML) and apical four chamber (MLa) views.

AP long and AP short dimensions were measured along the line of maximum distance between the transducer and the posterior boundary of the chamber; SIa dimensions were measured along the line between the upper point of the superior border of the cavity and the mid-point of the line joining the attachment points of the mitral leaflets to its ring; $M L$ and MLa dimensions were measured along the line of maximum distance between the interatrial septum and the lateral boundary of the left atrium. In most cases this line was perpendicular to AP in the short axis view and to SIa in the four chamber apical view. In the parasternal short axis and the apical four chamber views the left atrial appendage was carefully identified in real time and stop action review and excluded from actual ML and MLa. In the four chamber apical view the confluence of the pulmonary veins was not included as part of left atrium.

All measurements were taken on the frame proximal to the end of $T$ wave downslope showing the 
greatest atrial size (ventricular end systole). The atrial outlines were carefully traced by the light pen system as closely as possible to the inner border of the atrial wall. The wall echoes were excluded from actual measurements. A single atrial cycle was chosen for measurements. When the endocardial outlines were not complete in any single stop frame a frame by frame review was used to fill in areas of incomplete endocardial outlines of the best atrial cycle.

Measurements were made on the same image independently by two observers, and the mean value of these two measurements was taken as the actual measurement. Expressed as coefficient of variation 100 (standard deviation/mean) the interobserver variabilities were $5.8 \%, 5.6 \%, 6.5 \%, 6 \%, 6.2 \%$, and $6.4 \%$ for AP long, AP short, SI, SIa, ML, and MLa dimensions respectively, which are comparable to data previously reported. ${ }^{12} 14$

The light pen system was used to generate outlines of the left atrium in the parasternal long axis and apical four chamber views. These outlines were combined by the computer to calculate left atrial volume by Goerke's and Carlsson's modification of the Simpson's rule method. ${ }^{20}$ The SI dimension was considered the major axis of the chamber for purposes of identity between these two projections. ${ }^{15}$ Though not at right angles, we preferred to use the parasternal long axis and apical four chamber views, since it is difficult to standardise an apical two chamber view that is really perpendicular to the apical four chamber view.

\section{ANGIOGRAPHIC STUDIES}

Biplane angiographic visualisation of the left atrium was performed in anterior and left lateral projections by injection of Renografin $76(0.8-1.2 \mathrm{ml} / \mathrm{kg})$ into the main pulmonary artery. Good outlines of the left atrium were obtained in 19 patients.

Left atrial angiograms were traced in each patient at the end of ventricular systole, excluding the atrial appendage and the pulmonary veins. Left atrial volume was calculated from the stop frame images using the light pen system used to obtain cross sectional echocardiographic measurements. Goerke's and Carlsson's modification of the Simpson's rule method was used by the computer to calculate the angiographic left atrial volumes. ${ }^{20} 21$

Mitral valve regurgitation was graded in each patient using Sellers's scale of left ventricular angiography. ${ }^{22}$

\section{DATA ANALYSIS}

To evaluate the reliability of cross sectional echocardiographic estimates of left atrial size the following analyses were performed: left atrial volumes assessed by cross sectional echocardiography and angiocardiography were compared in 19 patients with mitral valve disease; and the anteroposterior diameter of the left atrium assessed by $M$ mode echocardiography was compared with the AP long and short dimensions obtained by cross sectional echocardiography in normal subjects and in patients with mitral valve disease. ${ }^{15}$

We did not compare cross sectional echocardiographic and angiographic left atrial dimensions because cross sectional echocardiographic and angiographic projections are not directly comparable. ${ }^{23}$ Left atrial SI and ML dimensions obtained from the parasternal approach were compared with SIa and MLa dimensions obtained from the apical approach.

All cross sectional echocardiographic left atrial dimensions for normal subjects were plotted against body surface area. The absolute values for normal subjects were compared with values in patients with mitral valve disease. To establish whether normal subjects and patients with mitral valve disease had different left atrial configurations we considered AP, SI, and ML dimensions separately in the two groups.

Statistical analysis of data was performed using Student's t test for unpaired data, chi squared test, and standard regression analysis when appropriate. Data are expressed as mean \pm standard deviation. The normal limits of the cross sectional echocardiographic left atrial dimensions refer to the second standard deviation of the control group. For regression analysis results are expressed in terms of correlation coefficient ( $r$ ) and, for comparing cross sectional echocardiographic and angiographic left atrial volumes, in terms of standard error of the estimate (SEE).

\section{Results}

Results refer to the 37 patients with mitral valve disease in whom satisfactory cross sectional echocardiographic recordings were obtained for determining all left atrial dimensions. In 17 out of 61 normal subjects (28\%) cross sectional echocardiography failed to show the upper border of the left atrium using the apical or the parasternal approach ${ }^{13}$; in seven subjects (11\%) cross sectional echocardiography failed to reveal the medial or lateral border of the left atrium using the parasternal short axis view.

Fig. 2 shows the good correlation found between cross sectional echocardiographic and angiographic left atrial volumes in 19 patients with mitral valve disease $(r=0.97)$.

The $M$ mode anteroposterior dimension of the left atrium correlated well with AP long and AP short dimensions obtained by cross sectional echocardiography ( $r=0.78$ and 0.84 , respectively) in normal subjects and in patients with mitral valve disease. Both $\mathrm{AP}$ long and AP short dimensions were shorter, 


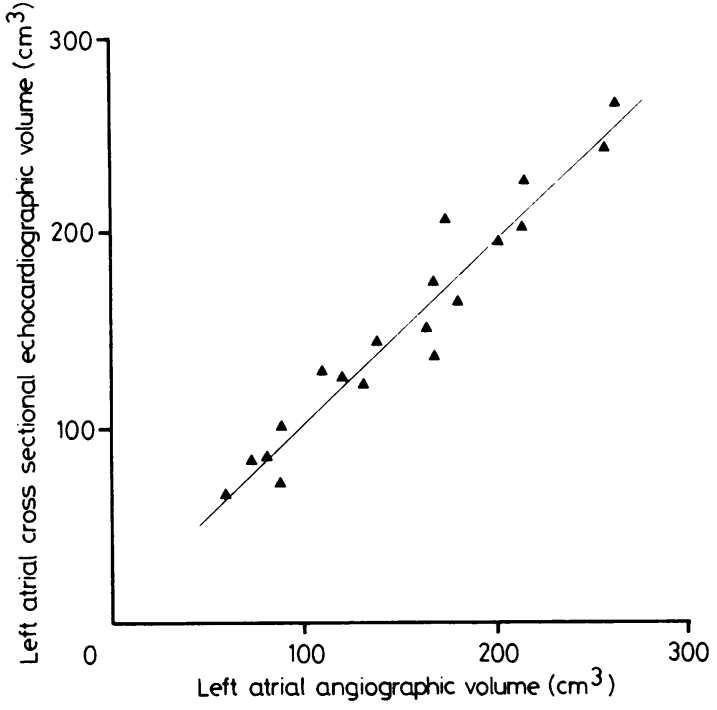

Fig. 2 Relation between angiographic and cross sectional echocardiographic left atrial volumes in 19 patients with mitral valve disease. Linear regression equation is $y=0.932 x+10 \cdot 28$ $(r=0.97, S E E=14.76)$.

although not significantly so, than the $M$ mode anteroposterior dimension because the latter did not include the posterior aortic root echo. ${ }^{13}$

Table 2 gives the values of cross sectional echocardiographic dimensions of the left atrium in normal subjects obtained with the parasternal and apical approach and these are compared with data of Schabelman et al. ${ }^{24}$ and Weyman. ${ }^{13} \mathrm{SIa}$ and MLa dimensions were significantly shorter than SI and ML dimensions $(p<0.001)$. In the parasternal projection
Table 3 Regression analysis of cross sectional echocardiographic left atrial dimensions and body surface area (BSA) in normal subjects

\begin{tabular}{llll}
\hline Regression equation & $r$ & $p$ \\
\hline AP short & $=15$ BSA+10.9 & 0.71 & $<0.001$ \\
SI & $=25$ BSA +6.8 & 0.52 & $<0.005$ \\
SIa & $=23$ BSA-2 & 0.43 & $<0.01$ \\
ML & $=19 \mathrm{BSA}+9.7$ & 0.54 & $<0.005$ \\
MLa & $=18 \mathrm{BSA}+1.5$ & 0.48 & $<0.01$ \\
\hline
\end{tabular}

For abbreviations of left atrial dimensions see Table 2 .

Table 4 Regression equations for the three parasternal left atrial dimensions in normal subjects and in patients with mitral valve disease

\begin{tabular}{llll}
\hline & & $r$ & \multicolumn{1}{l}{$p$} \\
\hline Normal subjects & $\mathrm{SI}=1.133 \mathrm{AP}$ short +20.58 & $0.64<0.001$ \\
& $\mathrm{ML}=0.729 \mathrm{AP}$ short +25.62 & $0.53<0.005$ \\
& $\mathrm{SI}=1.140 \mathrm{ML}+0.33$ & $0.88<0.001$ \\
& & & \\
Patients with & $\mathrm{SI}=0.888 \mathrm{AP}$ short +31.31 & $0.49<0.002$ \\
$\begin{array}{c}\text { mitral valve } \\
\text { disease }\end{array}$ & $\mathrm{ML}=0.622 \mathrm{AP}$ short +36.68 & $0.50<0.002$ \\
\hline
\end{tabular}

For abbreviations of left atrial dimensions see Table 2.

both SI and ML dimensions were significantly greater than AP dimensions in the short or long axis views $(p<0.001)$. SI and SIa dimensions were significantly greater than ML and MLa dimensions $(p<0.001)$. The correlations between left atrial dimensions and the body surface area in normal subjects were relatively low (Table 3 ).

Table 4 and Fig. 3, 4, and 5 show the regression analyses between AP short, SI, and ML dimensions in normal subjects. Left atrial dimensions were correlated with each other: a good correlation was found between SI and ML dimensions ( $r=0.88$ ), while these two dimensions had a relatively low correlation

Table 2 Left atrial dimensions assessed by $M$ mode and cross sectional echocardiography in normal subjects and in patients with mitral valve disease in this study and in previous investigations ${ }^{13} 14$

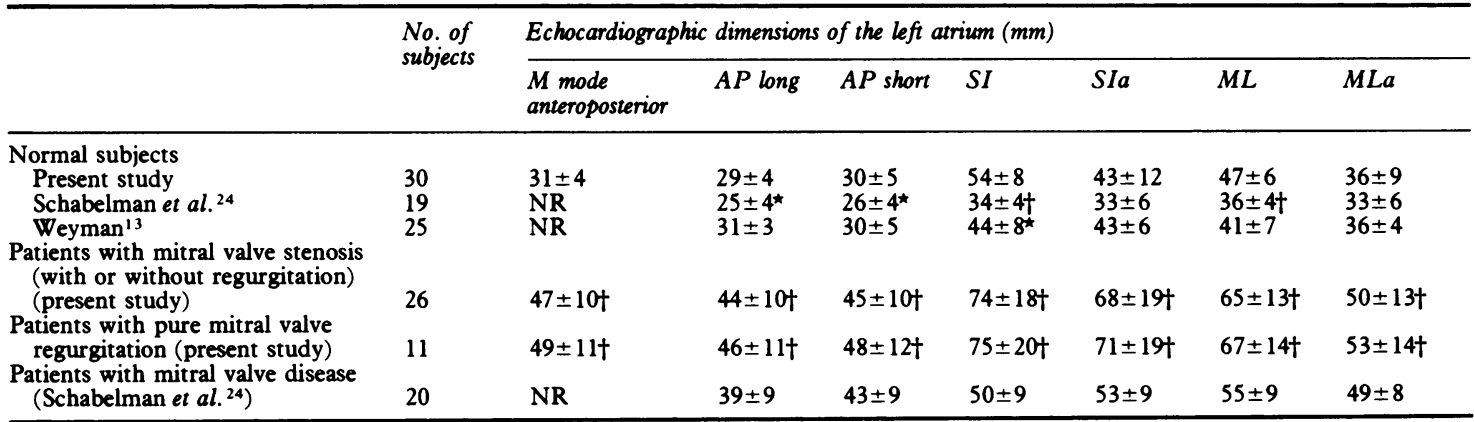

${ }^{\star} \mathrm{p}<0.01$ and $\mathrm{tp}<0.001 v$ normal controls in this study (unpaired Student's $t$ test).

AP long, anteroposterior dimension in the parasternal long axis view; AP short, anteroposterior dimension in the parasternal short axis view; SI, superior-inferior dimension in the parasternal long axis view; SIa, superior-inferior dimension in the apical four chamber view; ML, medial-lateral dimension in the parasternal short axis view; MLa, medial-lateral dimension in the apical four chamber view; NR not recorded. 


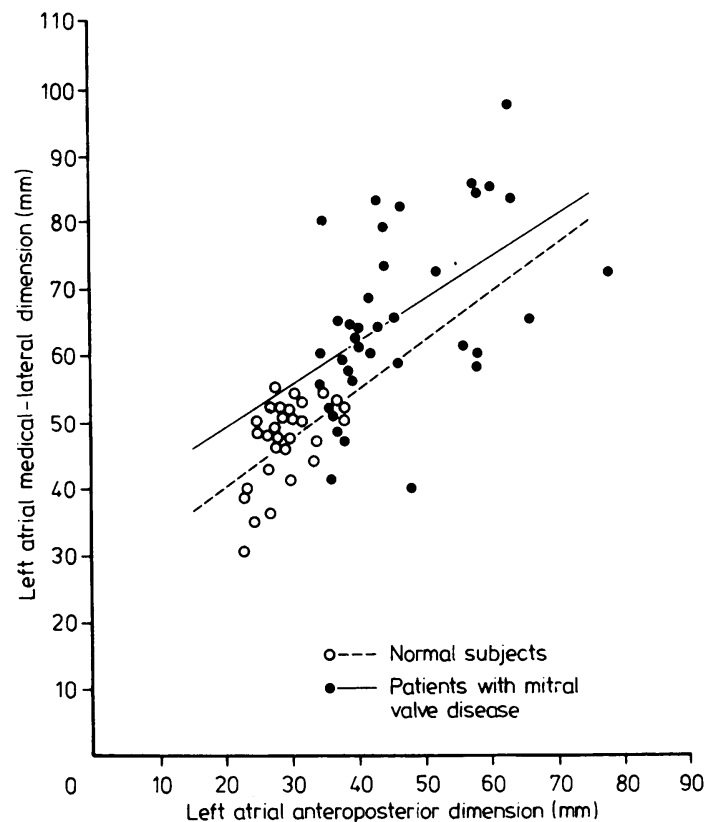

Fig. 3 Relation between left atrial medial-lateral and anteroposterior dimensions in the parastemal short axis view in normal subjects $(r=0.53 ; p<0.005)$ and in patients with mitral valve disease $(r=0.50 ; p<0.005)$. Linear regression equation for normal subjects is $y=0.72 x+25.6$ and for patients with mitral valve disease $y=0.62 x+36 \cdot 6$.

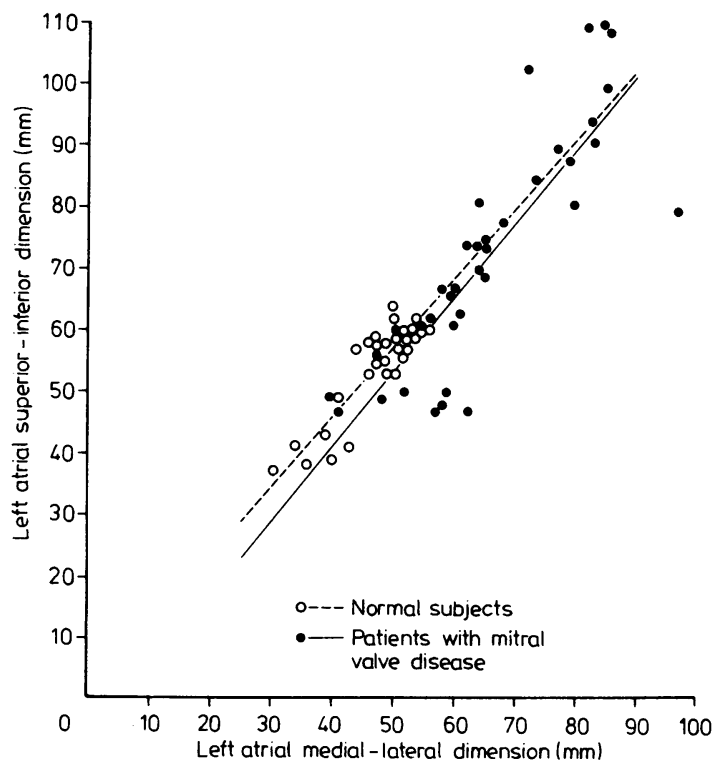

Fig. 5 Relation between left atrial superior-inferior and medial-lateral dimensions in the parasternal long and shor axis view respectively in normal subjects $(r=0.88 ; p<0.001)$ and in patients with mitral valve disease $(r=0.84 ; p<0.001)$. Linear regression equation for normal subjects is $y=1 \cdot 14 x+0.3$ and for patients with mitral valve disease $y=1 \cdot 22 x-7.4$.

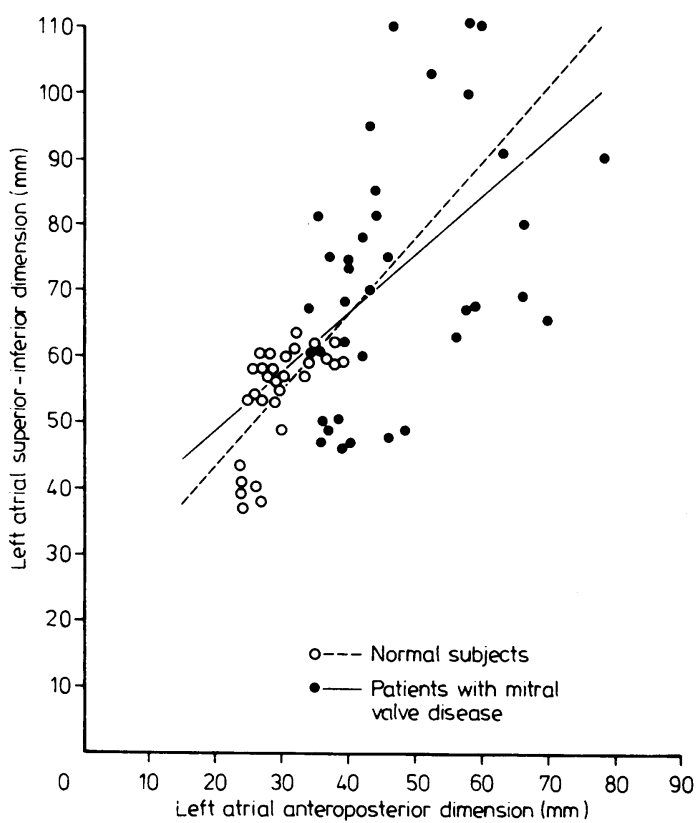

Fig. 4 Relation between left atrial superior-inferior and anteroposterior dimensions in the parastemal long and short axis view respectively in normal subjects $(r=0.64 ; p<0.001)$ and in patients with mitral valve disease $(r=0.49 ; p<0.002)$. Linear regression equation for normal subjects is $y=1 \cdot 13 x+20 \cdot 5$ and for patients with mitral valve disease $y=0 \cdot 88 x+31 \cdot 3$.

coefficient with AP dimensions in the short axis view $(\mathrm{r}=0.64$ and 0.53 , respectively).

Table 2 gives the cross sectional echocardiographic dimensions of the left atria of patients with mitral valve disease-subdivided into those with pure mitral valve regurgitation (11 patients) and those with mitral valve stenosis with or without associated valve regurgitation (26 patients). SI and ML dimensions were significantly greater than AP dimensions in the long axis and short axis views $(p<0.001)$; SI and $M L$ dimensions were not significantly different. SIa dimensions were significantly greater than MLa $(p<0.001)$. ML dimensions were significantly greater than MLa dimensions $(p<0.001)$.

Table 4 and Fig. 3, 4, and 5 give the regression analyses between AP short, SI, and ML dimensions in patients with mitral valve disease. A good correlation was found between SI and ML dimensions $(r=0.84)$, while SI and ML dimensions had a relatively poor correlation with AP dimensions in the short axis view $(r=0.49$ and 0.50 , respectively). Wide scatter of SI and ML dimensions compared with AP dimensions in the short axis view was found: patients with much increased SI or ML dimensions, or both, showed only moderately increased AP dimensions and vice versa (Fig. 3 and 4).

Each left atrial dimension was significantly greater in patients with mitral valve disease than in normal 
Table 5 Prevalence of abnormal left atrial dimensions at cross sectional echocardiography (parasternal projection) in patients with mitral valve disease

\begin{tabular}{|c|c|c|c|c|}
\hline & \multirow[t]{2}{*}{ No. of cases } & \multicolumn{3}{|c|}{ Abnormal left atrial dimensions } \\
\hline & & $A P$ short (39 mm) & $S I(59 \mathrm{~mm})$ & $M L(70 \mathrm{~mm})$ \\
\hline $\begin{array}{l}\text { Patients with three abnormal dimensions } \\
\text { Patients with two abnormal dimensions } \\
\text { Patients with one abnormal dimension } \\
\text { Patients without abnormal dimensions } \\
\text { Total }\end{array}$ & $\begin{array}{r}16 \\
10 \\
4 \\
7 \\
37\end{array}$ & $\begin{array}{l}16 \\
6 \\
3 \\
0 \\
25(67.6 \%)\end{array}$ & $\begin{array}{l}16 \\
4 \\
0 \\
0 \\
20(54 \cdot 1 \%)^{\star}\end{array}$ & $\begin{array}{l}16 \\
10 \\
1 \\
0 \\
27(73 \%)^{\star}\end{array}$ \\
\hline
\end{tabular}

ॠStatistically not significant $v$ other groups by chi squared $\mathrm{m} \times \mathrm{n}$ test.

Normal limits are 2 SD of the mean of the controls.

subjects $(p<0.001)$ (Table 2). Thirty of 37 patients with mitral valve disease had at least one abnormal left atrial dimension (Table 5): 25 (67.6\%) had abnormal AP dimensions in the short axis and 27 (73\%) had abnormal ML dimensions. In 16 out of the 37 patients with mitral valve disease (42.2\%) all three left atrial dimensions were increased. No patient had an abnormal SI dimension in the absence of increased AP in the short axis or ML dimensions.

\section{Discussion}

Although several studies have established the value of estimating left atrial size from the single anteroposterior dimension obtained by $M$ mode echocardiography,,$^{1-4}$ some limitations may affect the reliability of this method. In normal subjects the left atrium is an ovoid-elliptical shaped chamber, ${ }^{5620}$ and, although it tends to become more rounded when enlarged, ${ }^{25-29}$ a fixed relation between the various left atrial dimensions may be absent even when the chamber is dilated. ${ }^{7-10} 30$ Differences between the anteroposterior dimensions assessed using the $M$ mode parasternal approach and other left atrial dimensions assessed using the $M$ mode suprasternal approach or cross sectional echocardiography have been reported in patients with chest deformities, such as severe pectus excavatum, ${ }^{9}{ }^{30}$ mitral valve regurgitation, ${ }^{7}$ or mitral stenosis. ${ }^{15}$

Schabelman et al. ${ }^{14}$ reported a good correlation between cross sectional echocardiographic and angiographic left atrial volumes in 12 patients with a wide age range, suggesting that cross sectional echocardiography is superior to $M$ mode echocardiography for measuring left atrial size. No definitive data have been reported on the reliability of cross sectional echocardiography in determining left atrial dimensions, however, although measurements in cross sectional echocardiography have recently been standardised. 131731

Left atrial dimensions assessed by cross sectional echocardiography and angiocardiography are not directly comparable. ${ }^{32}$ We therefore used an indirect approach to examine the reliability of cross sectional echocardiographic estimates of left atrial dimensions: firstly, by comparing cross sectional echocardiographic and angiographic left atrial volumes in 19 patients with mitral valve disease, and, secondly, by assessing the correlation between cross sectional and $M$ mode echocardiographic estimates of the anteroposterior left atrial dimension in normal subjects and in patients with mitral valve disease. ${ }^{15} \mathrm{We}$ confirmed the excellent correlation found by Schabelman et al. ${ }^{14}$ between cross sectional echocardiographic and angiographic left atrial volumes. On the other hand, the correlation between the anteroposterior dimensions obtained by $M$ mode and cross sectional echocardiography was not good. Discrepancies might have been due in some cases to an atypical shape of the left atrium. For example, a triangular shape in the parasternal short axis view ${ }^{32}$ may result in substantial underestimation of the anteroposterior dimension due to an eccentric transection of the left atrium with the $M$ mode beam. ${ }^{15} 32$ More likely, sub-optimal definition of cross sectional images might have caused the differences between $M$ mode and cross sectional estimate of the left atrial AP dimension. Similar problems might have influenced the estimate of SI and ML dimensions. But only patients with good definition of all left atrial borders were selected for analysis. Moreover, the phased array system provides a lateral resolution of the order of $2-3 \mathrm{~mm} \cdot{ }^{33}{ }^{34}$ Consequently, these latter two measurements were considered to be reliable.

In our normal subjects the left atrial dimensions were significantly greater than those reported by Schabelman et al. ${ }^{14}$ but comparable to those reported by Weyman, ${ }^{13}$ except for the SI dimension assessed using the parasternal approach. This difference cannot be easily explained. Among the left atrial borders the superior is the most difficult to identify, particularly using the parasternal approach. ${ }^{13}$ Using a higher window than the standard, however, we were able to visualise this border correctly in nearly all normal sub- 
jects. Moreover, if we consider that an incorrect identification of the superior border of the left atrium is present almost exclusively in patients with considerable left atrial dilatation $(28 \%$ in our mitral valve disease group), it is unlikely that the difference between our data and those reported by Weyman might be attributed to an artifact. It is more likely that small differences in the exact timing of the ventricular end systole contributed to the variation in the SI dimension, which is usually the largest among the left atrial diameters.

Confirming previous investigations, ${ }^{6} 2126$ we found that in normal subjects the left atrium was oval, the SI dimension being the major axis and the ML and AP the minor axes; however, our data in normal subjects show that the left atrial configuration is not standard, confirming previous angiographic studies. ${ }^{6}$ In fact, at comparable AP values, a large variability of SI and ML values was observed.

The lack of a fixed relation between the three parasternal dimensions was more pronounced in patients with mitral valve disease. Although all left atrial dimensions were significantly greater in patients with mitral valve disease than in normal subjects, a certain degree of overlap was observed between the two groups when individual dimensions were considered.

According to the view that a dilated left atrium is spherical, ${ }^{513}$ any left atrial dimension should be sufficient to recognise a dilated chamber. Our data do not support this view. In fact, in only 16 of the 30 patients with left atrial enlargement was the left atrium dilated in all three dimensions, and, even though ML dimensions were more often increased than AP and SI dimensions, the presence and extent of chamber dilatation could not be predicted by the use of a single dimension. In particular, AP dimensions alone were not sensitive in recognising patients with mitral valve disease and left atrial enlargement. Of 30 patients with at least one left atrial dimension increased, five had normal AP values. Asymmetric enlargement of the left atrium was probably caused in some cases, as in patients with associated aortic valve disease, by aortic root dilatation, which prevents the anteroposterior expansion of the atrium; in others, as in those with associated tricuspid valve disease, a coexistent right atrial enlargement might have caused a superior-inferior dilatation of the left atrium, secondary to the compression of one chamber on the other. ${ }^{34}$

In conclusion, the left atrium does not have a standard configuration either in normal subjects or in patients with mitral valve disease and, consequently, no single echocardiographic dimension can predict the presence or absence of left atrial enlargement. A thorough examination of the left atrium by cross sec- tional echocardiography in patients with mitral valve disease should include the measurement of all three dimensions to determine the presence and measure the degree of left atrial dilatation.

We thank Luciano Gabrielli, Massimo Severi, and Mario Iannarelli for their technical assistance.

\section{References}

1 Hirata T, Wolfe SB, Popp RL, Helmen CH, Feigenbaum $\mathrm{H}$. Estimation of left atrial size using ultrasound. Am Heart f 1969; 78: 43-52.

2 Brown OR, Harrison DC, Popp RL. An improved method for echographic detection of left atrial enlargement. Circulation 1974; 50: 58-64.

3 Ten Cate FJ, Kloster FE, Van Dorp WG, Meester GT, Roelandt J. Dimensions and volumes of left atrium and ventricle determined by single beam echocardiography. Br Heart f 1974; 36: 737-46.

4 Lundstrom N, Mortensson W. Clinical applications of echocardiography in infants and children. II. Estimation of aortic root diameter and left atrial size: a comparison between echocardiography and angiocardiography. Acta Paediatr Scand 1974; 63: 33-41.

5 Hawley RR, Dodge HT, Graham TP. Left atrial volume and its changes in heart disease. Circulation 1966; 34: 989-96.

6 Levin AR, Frand M, Baltaxe HA. Left atrial enlargement. Correlation of left atrial volume with cardiac series, cine-esophagography, and electrocardiography. Radiology 1972; 104: 615-21.

7 Burgess J, Clark R, Kamigaki M, Cohn K. Echocardiographic findings in different types of mitral regurgitation. Circulation 1973; 48: 97-106.

8 Kronzon I, Mehta SS. Giant left atrium. Chest 1974; 65: 677-9.

9 Allen HD, Goldberg SJ. Usefulness of biaxial left atrium measurements by echocardiography [Abstract]. $\mathscr{F} C U$ 1974; 2: 222.

10 Lemire F, Tajik AJ, Hagler DJ. Asymmetric left atrial enlargement. An echocardiographic observation. Chest 1976; 69: 779-81.

11 Feigenbaum H. Echocardiography. 3rd ed. Philadelphia: Lea \& Febiger, 1981: 168-76.

12 Gradin-Frimmer G, Lassvik C, Nylander E, Wranne B. Echocardiographic estimation of left atrial size from the apical view. Eur Heart f 1982; 3: 159-63.

13 Weyman AE. Cross-sectional echocardiography. Philadelphia: Lea \& Febiger, 1982: 192-98, 498-501.

14 Schabelman SE, Schiller NB, Silverman NH, Ports TA. Left atrial volume estimation by two-dimensional echocardiography. Cathet Cardiovasc Diagn 1981; 7: $165-78$.

15 Kushner FG, Lam W, Morganroth J. Apex sector echocardiography in evaluation of the right atrium in patients with mitral stenosis and atrial septal defect. $\mathrm{Am}$ f Cardiol 1978; 42: 733-7.

16 Bommer W, Weinert L, Neumann A, Neef J, Mason DT, DeMaria A. Determination of right atrial and right ventricular size by two-dimensional echocardiography. Circulation 1979; 60: 91-100. 
17 DeMaria AN, Bommer W, Joye JA, Mason DT. Crosssectional echocardiography: physical principles, anatomical planes, limitations and pitfalls. Am F Cardiol 1980; 46: 1097-108.

18 Sahn DJ, DeMaria AN, Kisslo J, Weyman A. Recommendations regarding quantitation in M-mode echocardiography: results of a survey of echocardiographic measurements. Circulation 1978; 58: 1072-83.

19 Henry WL, DeMaria AN, Gramiak R, et al. Report of the American Society of Echocardiography Committee on nomenclature and standards in two-dimensional echocardiography. Circulation 1980; 62: 212-7.

20 Goerke RJ, Carlsson E. Calculation of right and left ventricular volumes: method using standard computer equipment and biplane angiocardiograms. Invest Radiol 1967; 2: 360-7.

21 Arcilla RA, Thilenius OG, Chiemmongkoltip P, Ranniger $\mathrm{K}$. Left atrial volume calculation by angiocardiography in children. Chest 1973; 63: 189-97.

22 Sellers RD, Levy MJ, Amplatz K, Lillehei CW. Left retrograde cardioangiography in acquired cardiac disease. Am $\mathcal{F}$ Cardiol 1964; 14: 437-47.

23 Schiller NB, Acquatella H, Ports TA, et al. Left ventricular volume from paired biplane two-dimensional echocardiography. Circulation 1979; 60: 547-55.

24 Schabelman SE, Schiller NB, Anschuetz RA, Silverman $\mathrm{NH}$, Glantz SA. Comparison of four two-dimensional echocardiographic views for measuring left atrial size [Abstract]. Am F Cardiol 1978; 41: 391.

25 Sauter HJ, Dodge HT, Johnston RR, Graham TP. The relationship of left atrial pressure and volume in patients with heart disease. Am Heart $\mathcal{F}$ 1964; 67: 635-42.

26 Murray JA, Kennedy JW, Figley MM. Quantitative angiocardiography. II. The normal left atrial volume in man. Circulation 1968; 37: 800-4.

27 Bruns HA, Brode P. Left atrial function studied by cineangiocardiographic volume determinations. I. Studies with casts of normal human atria. $A F R$ 1970; 110: 462-6.

28 Kennedy JW, Yarnall SR, Murray JA, Figley MM. Quantitative angiocardiography. IV. Relationships of left atrial and ventricular pressure and volume in mitral valve disease. Circulation 1970; 41: 817-24.

29 Bruns HA. Left atrial function studied by cineangiographic volume determination. II. Clinical application. AfR 1970; 110: 467-73.

30 Allen HD, Goldberg SJ, Sahn DJ, Ovitt TW, Goldberg BB. Suprasternal notch echocardiography. Assessment of its clinical utility in pediatric cardiology. Circulation 1977; 55: 605-12.

31 Geiser EA, Skorton DJ, Conetta DA. Quantification of left ventricular function by two-dimensional echocardiography: consideration of factors restricting image quality. Am Heart f 1982; 103: 905-10.

32 Gehl LG, Mintz GS, Kotler MN, Segal BL. Left atrial volume overload in mitral regurgitation: a twodimensional echocardiographic study. Am $\mathcal{F}$ Cardiol 1982; 49: 33-8.

33 Latson LA, Cheatham JP, Gutgesell HP. Resolution and accuracy in two-dimensional echocardiography. Am $\mathcal{f}$ Cardiol 1981; 48: 106-10.

34 Helak JW, Plappert T. Muhammad A, Reichek N. Two dimensional echographic imaging of the left ventricle: comparison of mechanical and phased array systems in vitro. Am F Cardiol 1981; 48: 728-35.

Requests for reprints to Dr Francesco Loperfido, Istituto di Cardiologia, Università Cattolica S Cuore, Policlinico A Gemelli, Largo Gemelli 8, 00168 Rome, Italy. 